\title{
"It just isn't a priority." Will primary science learning loss be forgotten?
}

\author{
Cherry Canovan (corresponding author), University of Central Lancashire \\ Email: ccanovan@uclan.ac.uk \\ Naomi Fallon, University of Central Lancashire \\ Email:nfallon6@uclan.ac.uk
}

\begin{abstract}
This study is part two of an ongoing investigation into the impacts of the UK's Covid-19 related school closures on primary science teaching and learning. In part one, conducted during the closures of spring 2020, we found that science teaching had suffered in ways that were likely to entrench inequality in who can access STEM education and careers.

The research reported in this paper, conducted during the second round of closures in early 2021, found that little progress had been made in mitigating science learning loss at primary level, with less than $10 \%$ of parents aware of any efforts in this regard. Meanwhile a concerning number of teachers were worried that reversing science learning loss was not a priority for schools, and/or reported that no efforts had been made to tackle this.
\end{abstract}

Parents felt that in general, home learning in the second closure period was much more effective than in 2020 . However science provision, although somewhat improved, was still perceived by many to be disappointing in quantity and/or quality. Teachers were still finding science a challenge to teach, although one major barrier from the first closures, a lack of access to IT, had largely been addressed.

The results show that a lack of 'catch-up' activity risks science learning loss being forgotten, while the second round of closures has likely exacerbated the relative learning loss in science over other 'core' subjects. Both these effects have negative implications for attempts to interest young people in STEM education and careers.

\section{Introduction}

In January 2021, faced with soaring Covid-19 cases nationwide, the UK government decided at short notice to close primary schools in England. This was the second round of closures, following those of spring/summer 2020, and lasted for eight school weeks.

Since the first closures began in March 2020, evidence has been emerging, both in the UK ${ }^{1-3}$ and around the world ${ }^{4-6}$, of related learning loss.

During the first closures, we studied how the move to home learning had affected science teaching and learning for primary-age children ${ }^{7}$. Surveying teachers and parents, we found that science teaching had disproportionately suffered, particularly in areas of high deprivation. We also found 
that the situation was likely to exacerbate existing inequalities in who can access science - results that were reported in the ASE's Education in Science magazine ${ }^{8}$.

Attention has now begun to focus on how best to repair the damage ${ }^{9,10}$. Reporting on 380 interim school visits carried out in September-October 2020, Ofsted ${ }^{11}$ found that many but not all schools had returned to teaching all subjects, but most were adapting the curriculum in response to pupils' knowledge gaps. However, they added that

Nearly all primary school leaders said that they were prioritising reading and mathematics, with very few schools focusing on science.

This is worrying, as research shows ${ }^{12}$ that young people's attitudes to science are largely fixed by the end of primary school. In our earlier paper, we argued that reversing science learning loss should be prioritised in order not to miss this window.

With the sudden advent of another round of home schooling, we decided to go back to our participants. We wanted to know how much learning loss parents and teachers perceived children to have suffered in science, and how this was being addressed. We also wanted to know how science provision in Closure Period 2 (CP2) differed from Closure Period 1 (CP1).

We aimed to address the following questions:

- How much learning loss in science was observed after CP1 by teachers and parents? How was this mitigated during the autumn term when children were back in the classroom?

- How did primary-level home learning differ between Closure Period 2 (CP2) and Closure Period 1 (CP1), both in general and for science specifically?

\section{Methods}

To answer the above questions, we approached parents and teachers who had participated in our earlier study (henceforth referred to as Phase 1) and had agreed to be contacted again. Those who agreed then completed a survey about their experiences with primary science teaching and learning in $\mathrm{CP} 2$.

Our Phase 1 study design proposed that Phase 2 would be completed "after schools return to normal teaching". However with another prolonged set of closures, we felt it important to gather real-time evidence of the impacts on primary science, together with a picture of how efforts to reverse learning loss had been progressing. The study outlined here is therefore Phase 2; we anticipate Phase 3 taking place during academic year 2021-22.

Our survey contained both quantitative and qualitative items. We received a total of 100 responses, 77 from parents and 23 from teachers, comprising $47 \%$ of the available pool. The original parent sample was skewed towards those with higher levels of science education, meaning that the current sample has the same bias. As the vast majority (74/77) of respondents were resident in England, this report is from the perspective of English education; differing education systems in the other UK nations mean that the results do not necessarily extrapolate to those areas.

To provide a uniform approach across both studies, we adhered to protocols from Phase 1 in which respondents remained anonymous. Both studies were approved by the appropriate ethics panel at the University of Central Lancashire. 


\section{Results}

\section{Learning loss}

We asked parents what learning loss their child had suffered in a range of subjects during CP1. Respondents were able to choose from a variety of options, and to choose more than one. By far the most common response was that children had experienced learning loss across the board; however science as a stand-alone option was chosen more frequently than English and maths. Those choosing 'other' mainly expressed issues such as lack of socialisation.

\section{In your opinion, did your child experience significant learning loss in the following subjects during CP1?}

Learning loss across the board

No learning loss

Science

Maths

English

Other

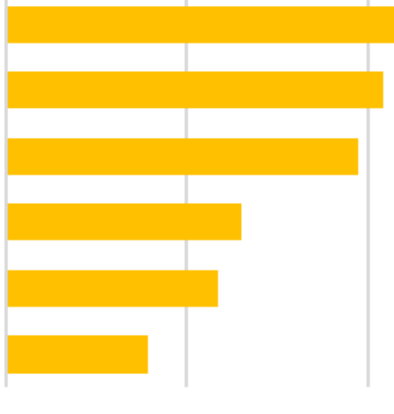

20

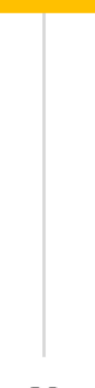

30

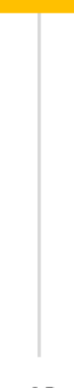

40

$\%$ of parents selecting response

Meanwhile all teachers observed learning loss in the three core subjects ${ }^{\mathrm{a}}$ when children returned to school in September 2020; although the option of 'no learning loss' was given, no respondents selected this. Significant learning loss was reported by more than half of respondents for science and maths, rising to $75 \%$ for English.

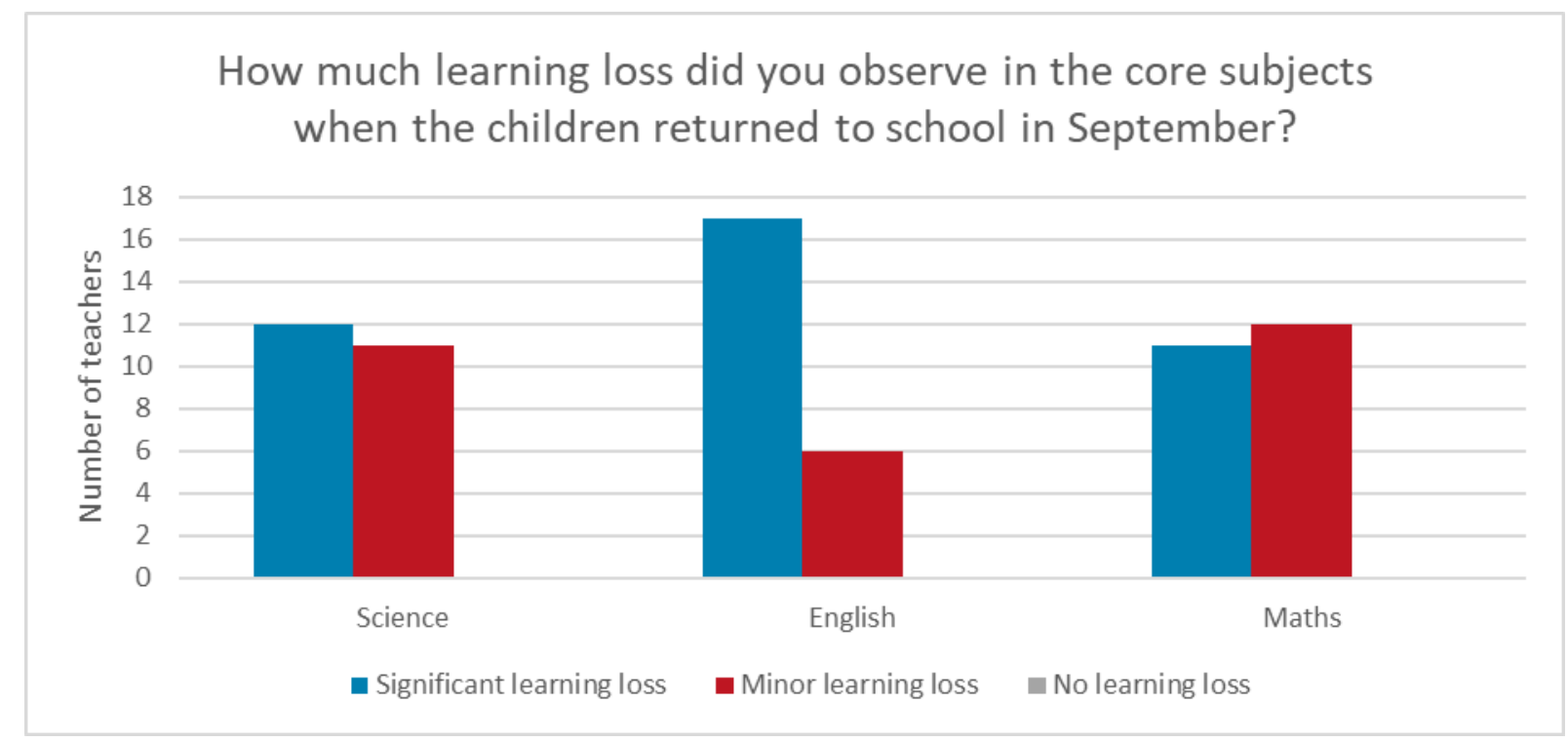

\footnotetext{
a In English schools, maths, English and science are defined as 'core' subjects, while other disciplines such as history, geography and music are categorised as 'foundation' subjects. Curricula differ across the other countries of the UK.
} 
We then asked both parents and teachers what mitigation or catch-up work had been used to tackle the reported learning loss, both for general learning and science specifically.

First we asked parents what steps their child's school had taken to mitigate general learning loss.

Around $60 \%$ of parents who responded reported that school had taken action of some sort, with the remainder split between 'None/None that I am aware of', and 'unsure/don't know'.

Opinions as to the efficacy of catch-up work varied widely. While some were very positive - "A lot of support has been provided by the school for academic and mental health needs," - others indicated that their child had suffered or been held back by efforts to make sure others were up to speed, or had been put under excessive pressure to catch up. Some knew that catch-up was happening but didn't know in what way: “I'm not sure to be honest. They just reassured us they would catch them up."

When we asked parents to name which subjects catch-up work had focused on, by far the most common were English and maths. Only one parent mentioned science, although a small number said all areas had been covered. As already mentioned, our parent respondent group had an overrepresentation of those with advanced science qualifications; it is likely, therefore, that they would be more aware of any science catch-up work provided than the general population.

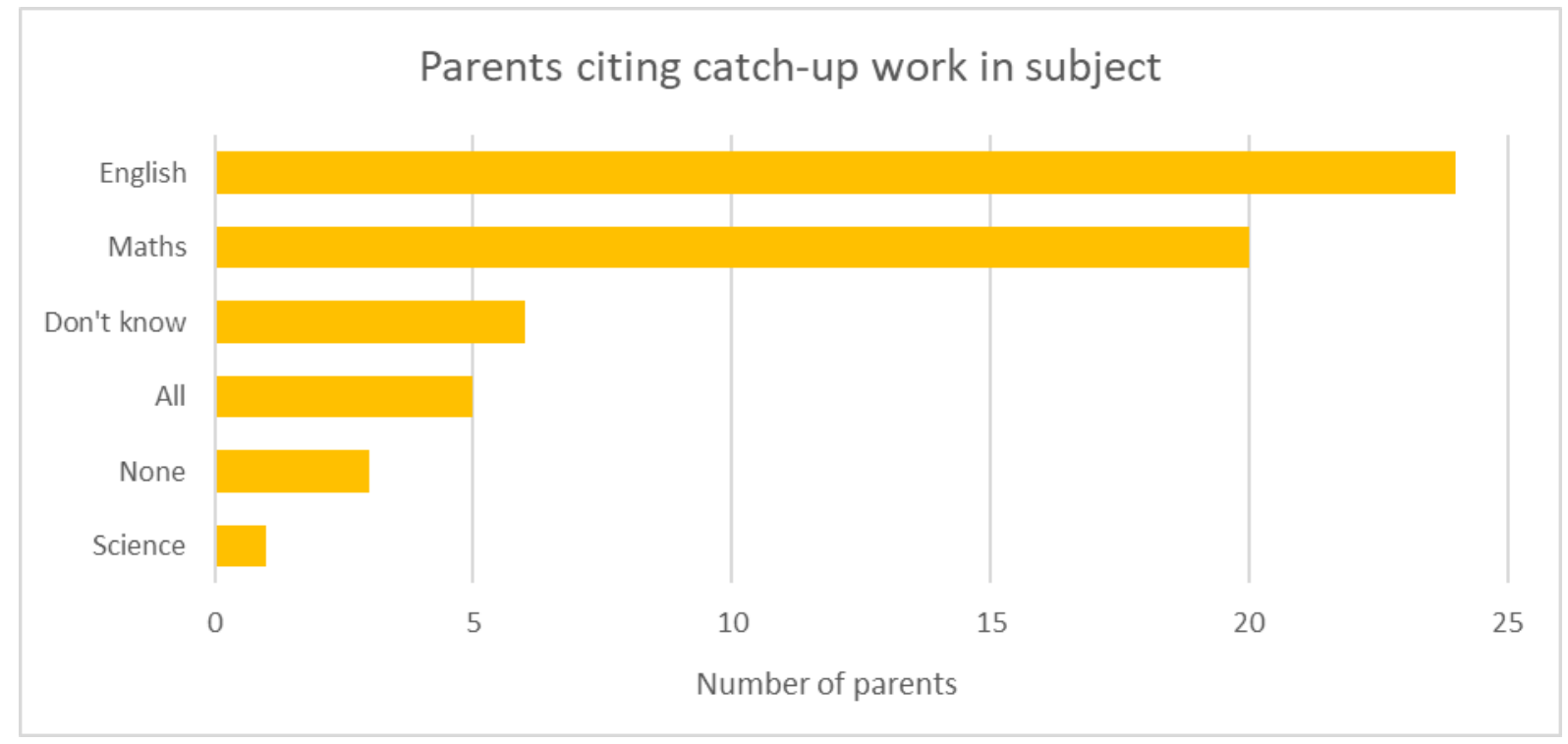

We then asked parents: "During the Autumn term, what steps, if any, were taken by the school to mitigate SCIENCE learning loss? There were two main groups of answers; those who said 'None' or 'None that I am aware of', and those that were unsure/didn't know. Only a very small number - less than $10 \%$ - were aware of any action taken by schools to counteract science learning loss. The difference between parents' reports of mitigation work generally and for science can be seen below. 


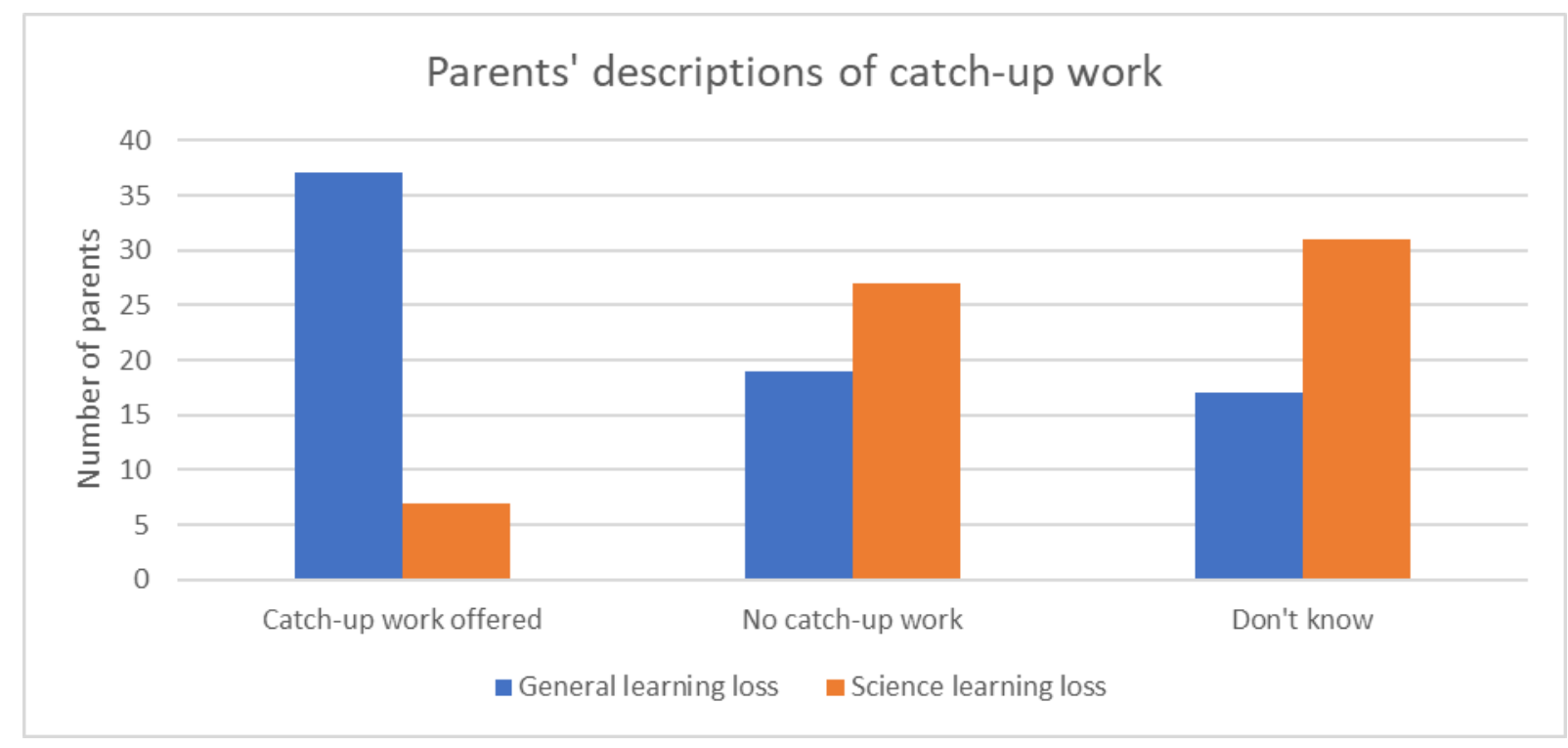

Teachers were asked to what extent they were able to mitigate learning loss, in both science and other subjects; overall, respondents felt that efforts to reverse losses in the core subjects had only been partly successful. Maths was the only subject where a few teachers felt they had been able to mitigate all learning loss; concerningly, in science, a fifth reported they had been unable to reverse any learning loss.

When asked about strategies to tackle general learning loss, many teachers reported that the usual curriculum was replaced with what some called a "recovery" curriculum, focusing on maths, English and areas identified as missed. Additional work or catch-up groups were also introduced, alongside targeted support for some pupils.

For learning loss in science specifically, a few teachers reported having taken specific initiatives such as extra teaching or curriculum adjustment, whilst for others this was integrated into the school's broader strategy. However a significant minority of our respondents - 10/23 - reported that no catch-up work for science had been planned or attempted. Several used phrases such as "I'm afraid it just isn't a priority."

Reflecting on how school closures had affected science teaching and learning at primary level, some teachers expressed concern that science learning loss would not receive the same attention as maths and English and so would persist:

Science was already a struggling subject in many schools, my fear is that a lot of teachers won't see the importance of it and just see that focusing on maths and English is the most important.

A couple of teachers reported secondary impacts on science learning through the loss of extracurricular activities such as science clubs and science weeks, and some suggested that future lesson planning and curricula would have to incorporate missed subject knowledge and skills development.

\section{Home learning in $\mathrm{CP} 2$}

As well as learning loss from CP1, we asked parents and teachers about their experiences of home learning in CP2. There was a broad consensus among parents that in general, home education resources provided during CP2 were an improvement on CP1, with only around $10 \%$ suggesting that provision had stayed the same or worsened. 
Participants were asked "How, if at all, does the remote education provided by your children's school during CP2 differ from that given in CP1?" Free text responses yielded a number of positive themes, including

- daily provision of content;

- live online lessons/meet-ups;

- schooling more structured/organised;

- greater volume of work provided;

- teachers giving more feedback on assignments.

A typical comment was:

...there was very little education in period 1 . Now it is structured with a daily timetable, prerecorded lessons, assignments to hand in with feedback given and live lessons every day.

In order to compare the two closure periods, we asked parents about the three core subjects, as well as one foundation subject, history, to act as a comparator. We asked parents whether they agreed that "School provided enough work, of a good quality"; as can be seen, perceptions on this point improved dramatically between CP1 and CP2, with satisfaction very high for maths and English in $\mathrm{CP} 2$. However science, although improved, continued to lag behind, with scores comparable to history.

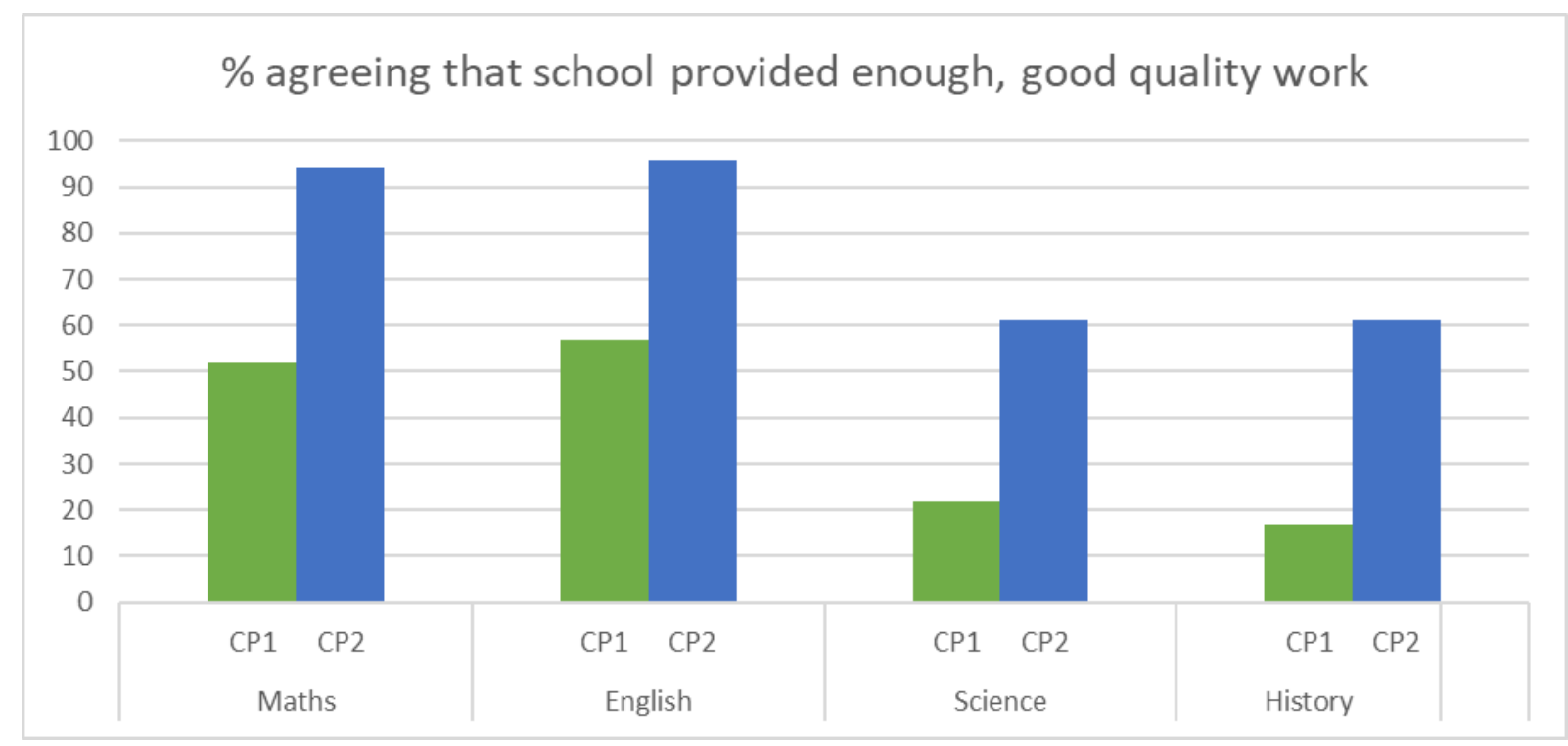

Although there was consensus that general teaching and learning in CP2 was greatly improved, there was much more variety of opinion when it came to the quantity and quality of science provision. Participants were asked two open-ended questions about science: "How, if at all, does the science education provided by your children's school during CP2 differ from that given in CP1?" and "Please tell us about any changes you perceive in the effectiveness of science teaching from CP1 to CP2."

Although a small majority of responses stated that science provision was somewhat improved being provided more regularly and/or of better quality - a quarter of responses stated that during $\mathrm{CP} 2$, science was either not taught at all or provision was very minimal, while another group questioned the quality of work provided. 
Positive responses included "There's more of it [science] and it's more structured," and "The work provided is much better quality and more doable at home." However such views were to a large extent offset by negative perceptions of quantity and/or quality by other parents.

Reports of no science teaching in either lockdown were depressingly common, with comments such as "CP1: non-existent. CP2: very minimal," and "I haven't been given anything for either lockdown." Where science teaching was provided, parents did not always find it satisfactory. The quantity of work was one issue highlighted:

She gets maths and English everyday so it would be nice to get some more science work.

Science is only covered as part of the curriculum every fortnight.

For other parents, quality was lacking. One reported that "We have been sent links to a couple of Operation Ouch ${ }^{\mathrm{b}}$ videos," while another noted that "[Provision] has improved, however, I do believe science has taken a back seat overall to maths and English." Some parents were disappointed by a lack of hands-on science activities: “...they haven't done anything very practical during CP2, more internet-based games, videos etc...".

Such responses may be due to continuing difficulties experienced by teachers in this area. During $\mathrm{CP} 1$, teachers reported three major barriers to science teaching - poor access to equipment, whether families could provide adequate resources, and concerns about parents' abilities to support science learning. In our Phase 2 survey, teachers were asked to what extent they had experienced these barriers in each closure period. The overwhelming majority reported that they were still experiencing these barriers; however there was some positive change. In CP1, all three aspects were cited as major barriers by the majority of teachers, while in CP2 parental ability to support science learning was the only barrier still cited as a major issue by more than half of teachers (59\%). In particular, around two-thirds of teacher respondents reported that IT/tech provision had been given to families in need. However several teachers felt that a new barrier - prioritisation of English and maths over science by both schools and families - had led children to disengage with science.

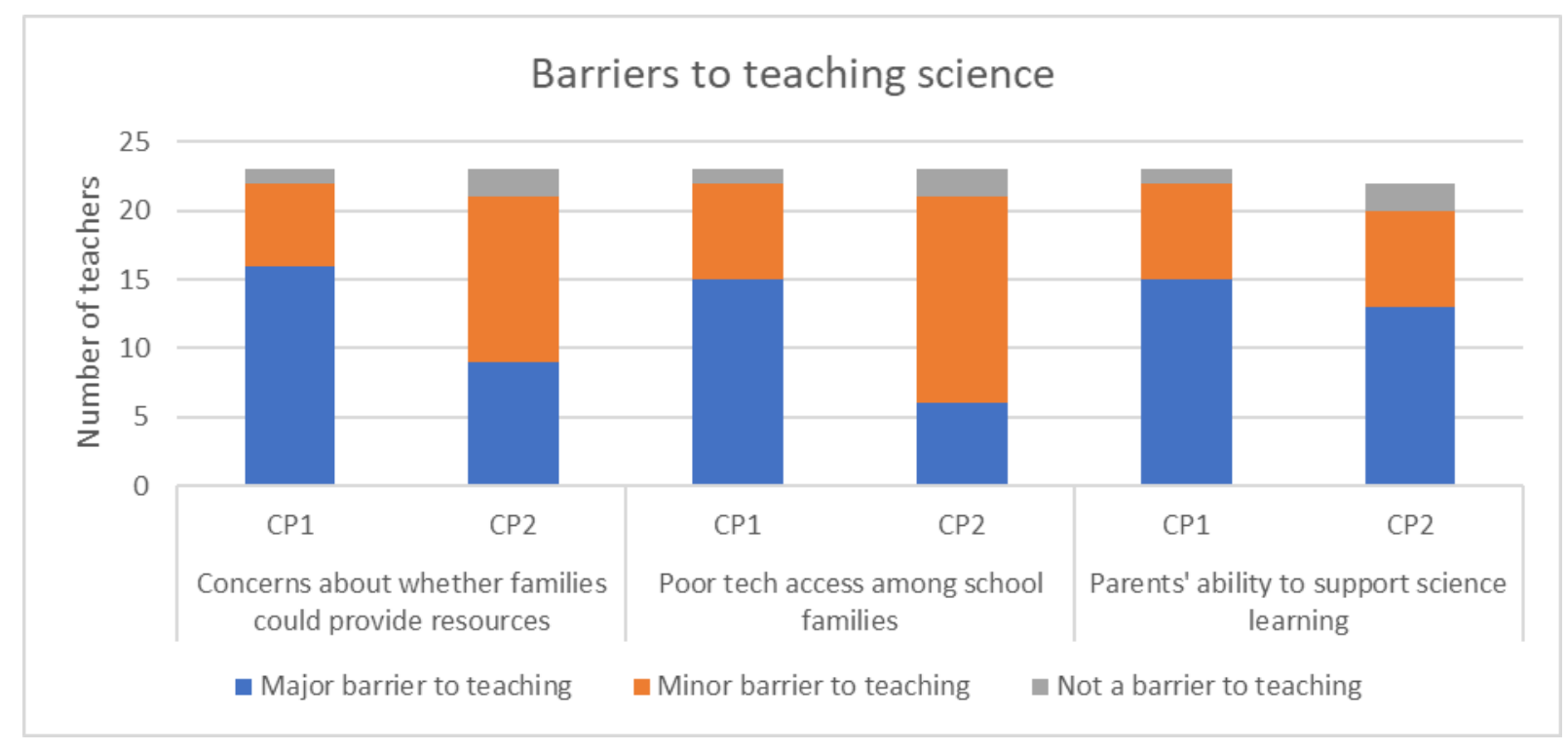

When asked how changes to working patterns such as more live teaching had impacted on science in $\mathrm{CP} 2$, around a quarter of teachers cited benefits: "[The] ability to question them effectively - explore

\footnotetext{
${ }^{b}$ A popular BBC show aimed at children and focusing on medical matters.
} 
what they already know and build upon." However around a half expressed difficulties and/or negative impacts. These included practical difficulties in teaching science through remote channels:

I am now completing a weekly live science lesson, however as all of our topics this year are very practical, I am finding this very difficult to carry out successfully.

Others reported being told not to include science in live lessons:

Science I miss teaching... I have been told by my school to send out Oak Learning videos so I'm not even teaching it anymore.

\section{Discussion and conclusions}

It is clear that parents and teachers are concerned about the learning loss arising from CP1. The majority of parents (57\%) felt that their child had suffered learning loss across the board, with more perceiving this for science than for maths or English. Although teachers felt that learning loss was most severe in English, all respondents had also witnessed learning loss in science.

Mitigation work, however, was not focused on science. Teachers felt that learning loss had been reversed most successfully in maths, while some stated that they had been unable to reverse any science learning loss at all. Parents were generally aware of efforts within school to provide catch-up activity, but this was heavily focused on maths and English. Less than $10 \%$ of parents were aware of any attempt by their school to address science learning loss.

Meanwhile whilst it is clear that in general, primary-level home education in CP2 was a great improvement on CP1, the picture is again less positive for science. Although a small majority of parents reported that more science was being taught and/or was of a better quality, a quarter said that their child received no science teaching in CP2, and a significant cohort reported poor quality provision. Whilst most parents agreed that in CP2 schools were providing enough, good quality work in maths and English, the figure was much lower for science and was more comparable to the assessment of history work, a foundation rather than core subject.

As in CP1, meanwhile, teachers continued to find it difficult to teach science. Although some of the barriers identified by teachers in spring 2020 had been mitigated, particularly by the widespread provision of IT equipment to families in need, these were still all experienced to some extent by nearly all teachers. The increased demands of provision in CP2 had brought its own challenges, with half reporting that the new way of working had negatively impacted in some way on their ability to teach science.

In our earlier paper, we found evidence that teaching and learning science at primary level had been particularly difficult in CP1, and argued that this needed to be addressed as a matter of urgency, because young people's attitudes to science are largely fixed by the end of primary school. Sadly, our study of primary science in CP2 shows that, while provision was improved in some cases, many difficulties remained compared to other subjects, meaning that relative learning loss was likely exacerbated. Meanwhile work to reverse learning loss has been heavily focused on maths and English, with very little attempt to turn things around in science. Unless concerted action is taken over the next academic year, primary science learning loss risks being forgotten, with the result that more young people will be excluded from STEM learning and careers. 


\section{References}

1. Andrew A, Cattan S, Dias MC, et al. Inequalities in Children's Experiences of Home Learning during the COVID-19 Lockdown in England.; 2020. https://www.ifs.org.uk/publications/14975

2. Cullinane C, Montacute R. COVID-19 and social mobility impact brief \#1: School shutdown. Sutt Trust. 2020;(April):1-11. https://www.suttontrust.com/our-research/covid-19-and-socialmobility-impact-brief/

3. Rose S, Twist L, Lord P, et al. Impact of School Closures and Subsequent Support Strategies on Attainment and Socio-Emotional Wellbeing in Key Stage 1: Interim Paper 1.; 2021. https://www.nfer.ac.uk/impact-of-school-closures-and-subsequent-support-strategies-onattainment-and-socio-emotional-wellbeing/

4. Engzell P, Frey A, Verhagen MD. Learning Loss Due to School Closures During the COVID-19 Pandemic. Published online 2021. OSF.IO/VE4Z7

5. Lichand G, Alberto Doria C, Leal Neto O, Cossi Fernandes JP. The Educational Impacts of School Closures and Reopening in the Pandemic: Evidence from Brazil. SSRN Electron J. Published online May 5, 2021.

https://papers.ssrn.com/sol3/papers.cfm?abstract id=3841775

6. Maldonado JE, De Witte K. The effect of school closures on standardised student test outcomes. FEB Res Rep Dep Econ. 2020;(September). https://lirias.kuleuven.be/3189074

7. Canovan C, Fallon N. Widening the divide: the impact of school closures on primary science learning. SN Soc Sci. 2021;1(5):117. https://link.springer.com/article/10.1007/s43545-021$\underline{00122-9}$

8. Canovan C. The effect of school closures on primary science education - a study. Education in Science. Published 2020. Accessed May 21, 2021.

https://www.ase.org.uk/resources/education-in-science/issue-282/effect-of-school-closuresprimary-science-education---study

9. Sutton Trust. Fairness First: Social Mobility, Covid and Education Recovery.; 2021. Accessed May 21, 2021. https://www.suttontrust.com/wp-content/uploads/2021/05/Fairness-FirstSocial-Mobility-Covid-Education-Recovery.pdf

10. British Academy. Shaping the COVID Decade: Addressing the Long-Term Societal Impacts of COVID-19.; 2021.

11. Ofsted. COVID-19 Series: Briefing on Schools, October 2020.; 2020.

https://assets.publishing.service.gov.uk/government/uploads/system/uploads/attachment d ata/file/933490/COVID-19 series briefing on schools October 2020.pdf

12. Archer L, Osborne J, DeWitt J, Dillon J, Wong B, Willis B. Young people's science and career aspirations, age $10-14$. Aspires. Published online 2013.

https://www.kcl.ac.uk/ecs/research/aspires/aspires-final-report-december-2013.pdf 